\title{
The Effect of Abdominal Visceral Fat, Circulating Inflammatory Cytokines, and Leptin Levels on Reflux Esophagitis
}

\author{
Su Youn Nam, ${ }^{1,2 *}$ II Ju Choi, ${ }^{3 *}$ Kum Hei Ryu, ${ }^{1}$ Bum Joon Park, ${ }^{1}$ Young-Woo Kim, ${ }^{3}$ Hyun Beom Kim ${ }^{4}$ and Jeongseon Kim ${ }^{5}$ \\ ${ }^{1}$ Center for Cancer Prevention and Detection, National Cancer Center, Goyang, Gyeonggi-do, Korea; ${ }^{2}$ Center for Gastric Cancer, Kyungpook \\ National University Hospital, Daegu, Korea; and ${ }^{3}$ Center for Gastric Cancer, ${ }^{4}$ Department of Radiology, ${ }^{5}$ Molecular Epidemiology Branch, \\ Division of Cancer Epidemiology and Prevention, National Cancer Center, Goyang, Gyeonggi-do, Korea
}

\section{Background/Aims}

Although adipocytes secrete inflammatory cytokines and adipokines, their role in reflux esophagitis is controversial. We investigated the association between visceral fat and inflammatory cytokines or adipokines in reflux esophagitis.

\section{Methods}

Abdominal visceral fat and cytokines were measured in 66 individuals with reflux esophagitis and 66 age- and sex-matched controls. The mean values for visceral fat and cytokines were compared in cases and controls. Second, correlations between visceral fat and inflammatory cytokines were measured. Finally, multiple logistic regression models for odds ratios (ORs) and 95\% confidence intervals (Cls) were used to estimate the effects of visceral fat and cytokines on reflux esophagitis.

\section{Results}

Visceral fat, leptin, interleukin (IL)-6, and IL-1 $\beta$ were higher in reflux esophagitis compared to controls. Visceral fat showed a strong positive correlation with IL-6 $(r=0.523, P<0.001)$, IL-8 $(r=0.395, P<0.001)$, and IL-1 $\beta(r=0.557, P<0.001)$, and a negative correlation with adiponectin $(r=-0.466, P<0.001)$. With adjusted analysis, visceral fat 100 (OR, $4.32 ; 95 \%$ $\mathrm{Cl}, 2.18-8.58 ; P<0.001)$ and leptin $(\mathrm{OR}, 1.36 ; 95 \% \mathrm{Cl}, 1.10-1.69 ; P=0.005)$ independently increased the risk of reflux esophagitis, but the effects of other cytokines were abolished.

Received: October 2, 2014 Revised: December 15, 2014 Accepted: December 26, 2014

(c) This is an Open Access article distributed under the terms of the Creative Commons Attribution Non-Commercial License (http://creativecommons. org/licenses/by-nc/3.0) which permits unrestricted non-commercial use, distribution, and reproduction in any medium, provided the original work is properly cited.

*Correspondence: Su Youn Nam and II Ju Choi are equally responsible for this study.

Su Youn Nam, MD, PhD

Center for Gastric Cancer, Kyungpook National University Hospital, 807, Hoguk-ro, Buk-gu 702-911, Daegu, Korea

Tel: +82-53-200-1620, E-mail: mascha@medimail.co.kr

II Ju Choi, MD, PhD

Center for Gastric Cancer, National Cancer Center, 323 Ilsan-ro, Ilsan dong-gu, Goyang, Gyeonggi-do 411-769, Korea Tel: +82-31-920-2282, Fax: +82-31-920-1127, E-mail: cij1224@ncc.re.kr

Financial support: This study was supported in part by grants (NCC 0810200, 1010190, and 0910220) from the National Cancer Center, Korea. The funding source had no role in the design, analysis, or interpretation of the study or in the decision to submit the manuscript for publication. The funding source had a role in collection of questionnaires and measurement of abdominal fat with CT scans (NCC 0810200), measurement of cytokines (NCC 1010190), and collection of serum samples (NCC 0910220).

Conflicts of interest: None.

Author contributions: Su Youn Nam and II Ju Choi contributed to the study design; Su Youn Nam, II Ju Choi, Kum Hei Ryu, Bum Joon Park, Young Woo Kim, Hyun Beom Kim, and Jeongseon Kim contributed to the implementation and supervision of the study; Su Youn Nam and II Ju Choi analyzed the data and take responsibility for the accuracy of the data analysis; and Su Youn Nam, Kum Hei Ryu, and Bum Joon Park performed all endoscopic procedures. All authors participated in the writing of the manuscript. Su Youn Nam and II Ju Choi had full access to the data in the study. All authors approved the final version of the manuscript.

ORCID: IL Ju Choi, http://orcid.org/0000-0002-8339-9824. 


\section{Conclusions}

Visceral fat may increase the risk of reflux esophagitis by increasing the levels of inflammatory cytokines. Leptin showed a positive association with reflux esophagitis that was independent of visceral fat.

(J Neurogastroenterol Motil 2015;21:247-254)

\section{Key Words}

Adipokines; Cytokines; Esophagitis

\section{Introduction}

Gastroesophageal reflux disease (GERD) is a major health problem in Western countries ${ }^{1}$ and has increased in Asian countries over the past decades. ${ }^{2,3}$ Several studies have suggested that abdominal obesity and visceral fat increased the risk of reflux esophagitis $^{4-6}$ or Barrett's esophagus. ${ }^{7}$ Abdominal visceral adipose tissue not only mechanically disrupts the integrity of the gastroesophageal junction barrier and leads to increased esophageal reflux ${ }^{8}$ but also has a metabolic effect. ${ }^{9}$ Abdominal visceral fat is metabolically active and increased inflammatory cytokines, insulin resistance, ${ }^{9}$ and cardiovascular disease. ${ }^{10}$ The inflammatory cytokines released from adipose tissue may increase the risk of esophageal inflammation, Barrett's esophagus, and esophageal adenocarcinoma. ${ }^{11,12}$ However, simultaneous evaluation of visceral fat and inflammatory cytokines to assess the effect on reflux esophagitis has not been reported.

In this study, we measured the abdominal fat volume and cytokines in 66 individuals with reflux esophagitis and 66 age- and sex-matched controls who underwent a health check-up to investigate the effects of visceral fat and inflammatory cytokines on reflux esophagitis.

\section{Materials and Methods}

\section{Study Population and Questionnaires}

A comprehensive health screening program was launched at the Korean National Cancer Center in May 2001. ${ }^{13}$ Participants were enrolled from the "abdominal obesity and gastrointestinal disorder study." ${ }^{4}$ In summary, among those who participated in the comprehensive health screening program and also underwent an abdominal fat computed tomography (CT) scan between February 2008 and November 2008, we excluded patients with previous gastric surgery, those who did not undergo the Helico- bacter pylori test, and current users of proton pump inhibitors. Participants with reflux esophagitis and age- and sex-matched controls were selected. Controls defined as absence of reflux esophagitis on endoscopy and absence of acid regurgitation or heartburn. Finally, we selected participants who agreed to undergo additional blood sampling for the study. Two well-trained research nurses interviewed participants who independently completed all questionnaires before the screening examinations. Smoking and alcohol consumption status were each classified as current (daily or occasionally) and not current.

The National Cancer Center Institutional Review Board approved the study (protocol number NCCNCS-10351), and all participants provided written informed consent for the use of personal data for research.

\section{Endoscopy}

Esophagogastroduodenoscopy was performed using a flexible endoscope (Q260; Olympus Optical, Tokyo, Japan) after overnight fasting. Reflux esophagitis defined as proven reflux esophagitis excluding minor change. The severity of reflux esophagitis was graded from A to D according to the Los Angeles classification system. Four gastroenterologists specializing in endoscopy performed all endoscopic procedures blinded to the questionnaire results. The kappa values for reflux esophagitis for the 4 readers were 0.86 for grade A, 0.93 for grade B, and 0.91 for grade C. ${ }^{4}$ During each endoscopic examination, rapid urease test (Pronto Dry; Medical Instruments, Solothurn, Switzerland) using a biopsy specimen obtained at the greater curvature of the body was done to evaluate $H$. pylori.

\section{Measurement of Obesity}

Weight and height measurements were automated (X-SCAN PLUS II, Jawon Medical Co, Kyungsan City, Korea), and body mass index (BMI) was calculated as weight divided by height squared $\left(\mathrm{kg} / \mathrm{m}^{2}\right)$. Trained nurses measured waist circumference at the midpoint between the lower borders of the rib cage and the 
upper pole of the iliac crest. ${ }^{4}$

Participants underwent $\mathrm{CT}$ in a supine position using a 64-multidetector CT (Brilliance 64; Philips, Best, Netherlands). ${ }^{4}$ In a brief summary, Contiguous 5-mm slices were acquired, and fat volume was measured using 20 slices covering $100 \mathrm{~mm}$ from $50 \mathrm{~mm}$ above to $50 \mathrm{~mm}$ below the umbilicus. Abdominal fat compartments were manually traced in each image, segmentation of the 20 slices was automatically reconstructed, and volume $\left(\mathrm{cm}^{3}\right)$ was calculated using software that electronically determined the area by setting attenuation values for a region of interest within a range of 25 to -175 Hounsfield units. Visceral fat was defined as intra-abdominal fat bound by parietal peritoneum or transversalis fascia, excluding the vertebral column and paraspinal muscles. The subcutaneous adipose tissue volume was obtained by subtracting the visceral adipose tissue volume from the total adipose tissue volume.

\section{Measurement of Serum Cytokines}

On the day of comprehensive screening, blood samples were collected from the participants who agreed to additional blood sampling. Within 4 hours, serum, plasma, and the buffy coat were isolated from whole blood and stored in a $-80^{\circ} \mathrm{C}$ freezer until use. Independent persons with no knowledge of the clinical information measured interleukin (IL)-6 (D6050; R\&D, Minneapolis, MN, USA), CXCL8/IL-8 (D8000C; R\&D), leptin (DLP00; R\&D), CCL5/RANTES (hRANTES; R\&D), adiponectin (DRP300; R\&D), and IL-1 $\beta / \mathrm{IL}-1 \mathrm{~F} 2$ (DLB50; $\mathrm{R} \& \mathrm{D})$ with ELISA kits. All measurements were done in triplicate according to the instruction guide.

\section{Statistical Methods}

The Pearson chi-square test or an independent $t$ test was performed to assess the difference in risk between the 2 groups (presence vs absence of reflux esophagitis). Spearman's test was employed to assess the correlation between visceral fat (visceral fat/total fat) and inflammatory cytokines. The effects of visceral fat volume and inflammatory cytokines on reflux esophagitis were estimated with odds ratios (ORs) and 95\% confidence intervals (CIs) using logistic regression analysis. Significant risk factors in the $t$ test or chi-square test were subjected to multivariate analysis. To assess ORs, we modified the variables because the value of visceral fat volume is measured in hundreds to thousands $\mathrm{cm}^{3}$ $\left(179-1798 \mathrm{~cm}^{3}\right), \mathrm{IL}-1 \beta$ is around $1 \mathrm{pg} / \mathrm{mL}(0.2-1.8)$, and IL-8 is $22-381 \mathrm{pg} / \mathrm{mL}$. Visceral fat $(/ 100)$ means that the visceral fat value was divided by 100 , IL-8 (/10) indicates that the variable was divided by 10 , and IL- $1 \beta(\times 10)$ indicates a 10 -fold value of IL-1 $\beta$. Therefore OR of visceral fat $(/ 100)$ means the risk of reflux esophagitis every increase of $100 \mathrm{~cm}^{3}$ of visceral fat.

We used STATA software (version 12; College Station, TX, USA) for our analyses. All statistical tests were two-sided, and $P$ $<0.05$ was considered statistically significant.

Table 1. Characteristics of Participants

\begin{tabular}{|c|c|c|c|}
\hline & $\begin{array}{l}\text { Control } \\
(\mathrm{n}=66)\end{array}$ & $\begin{array}{l}\text { Reflux esophagitis } \\
\qquad(\mathrm{n}=66)\end{array}$ & $P$-value \\
\hline Male (n [\%]) & $44(66.7)$ & $44(66.7)$ & 1.000 \\
\hline Age (mean [SD], yr) & $45.6(7.0)$ & $47.9(7.5)$ & 0.061 \\
\hline Body mass index (mean $[\mathrm{SD}], \mathrm{kg} / \mathrm{m}^{2}$ ) & $22.8(2.2)$ & $25.8(3.1)$ & $<0.001$ \\
\hline Waist circumference (mean $[\mathrm{SD}], \mathrm{cm}$ ) & $81.8(5.2)$ & $90.0(7.7)$ & $<0.001$ \\
\hline \multicolumn{4}{|l|}{ Visceral fat (mean $\left.[\mathrm{SD}], \mathrm{cm}^{3}\right)$} \\
\hline Total & $624.1(229.4)$ & $1145.1(356.3)$ & $<0.001$ \\
\hline Men & $742.8(175.3)$ & $1293.7(236.5)$ & $<0.001$ \\
\hline Women & $386.5(106.4)$ & $847.7(373.4)$ & $<0.001$ \\
\hline \multicolumn{4}{|l|}{ Visceral fat/total fat (mean $[\mathrm{SD}]$ ) } \\
\hline Total & $0.30(0.08)$ & $0.38(0.09)$ & $<0.001$ \\
\hline Men & $0.35(0.04)$ & $0.42(0.06)$ & $<0.001$ \\
\hline Women & $0.19(0.03)$ & $0.30(0.07)$ & $<0.001$ \\
\hline Current smoker (n [\%]) & $19(28.8)$ & $24(36.4)$ & 0.353 \\
\hline Current drinker (n [\%]) & $46(69.7)$ & $53(80.3)$ & 0.159 \\
\hline Presence of hiatal hernia (n [\%]) & $1(1.5)$ & $5(7.6)$ & 0.095 \\
\hline Presence of H. pylori (n [\%]) & $45(68.2)$ & $21(31.8)$ & $<0.001$ \\
\hline
\end{tabular}

$\mathrm{SD}$, standard deviation; H. pylori, Helicobacter pylori. 


\section{Results}

\section{Characteristics of Participants}

Sixty-six persons with reflux esophagitis and 66 age- and sex-matched controls were selected from consecutive health check-up participants. BMI, waist circumference, abdominal visceral adipose tissue volume, the ratio of visceral fat/total fat, and absence of $H$. pylori were higher in participants with reflux esophagitis (Table 1). Most participants with reflux esophagitis had mild esophagitis, including $82 \%$ with grade $\mathrm{A}(\mathrm{n}=54), 15 \%$ with grade $B(n=10)$, and $3 \%$ with grade $C(n=2)$.

\section{Expression of Inflammatory Cytokines in Reflux Esophagitis}

IL-6 (2.70 vs $3.37 \mathrm{pg} / \mathrm{mL})$, leptin (3.92 vs $6.55 \mathrm{ng} / \mathrm{mL}$ ), and IL-1 $\beta$ (0.89 vs $1.07 \mathrm{pg} / \mathrm{mL}$ ) were significantly increased in persons with reflux esophagitis, and IL-8, CCL5, and adiponectin had no difference between participants with reflux esophagitis and controls (Table 2). In men with reflux esophagitis, leptin and IL-1 $\beta$ were significantly increased, but adiponectin was decreased. Results were similar in women. Leptin had the strongest and most constant effect on reflux esophagitis in both overall and sex-specific analysis.
Table 2. Cytokine Levels Measured With ELISA in Participants

\begin{tabular}{lccr}
\hline & Control & $\begin{array}{c}\text { Reflux } \\
\text { esophagitis }\end{array}$ & $P$-value \\
\hline Total $(\mathrm{mean}[\mathrm{SD}])$ & $(\mathrm{n}=66)$ & $(\mathrm{n}=66)$ & \\
IL-6 $(\mathrm{pg} / \mathrm{mL})$ & $2.70(2.13)$ & $3.37(1.80)$ & 0.052 \\
IL-8 $(\mathrm{pg} / \mathrm{mL})$ & $62.98(83.20)$ & $60.47(62.15)$ & 0.844 \\
Leptin $(\mathrm{ng} / \mathrm{mL})$ & $3.92(3.40)$ & $6.55(5.11)$ & $<0.001$ \\
CCL5 $(\mathrm{ng} / \mathrm{mL})$ & $72.03(46.72)$ & $67.94(32.19)$ & 0.560 \\
Adiponectin $(\mu \mathrm{gg} / \mathrm{mL})$ & $6.78(4.21)$ & $5.70(5.84)$ & 0.226 \\
IL-1 $\beta(\mathrm{pg} / \mathrm{mL})$ & $0.89(0.35)$ & $1.07(0.43)$ & 0.010 \\
\hline Men $(\mathrm{mean}[\mathrm{SD}])$ & $(\mathrm{n}=44)$ & $(\mathrm{n}=44)$ & \\
IL-6 $(\mathrm{pg} / \mathrm{mL})$ & $3.07(2.49)$ & $3.82(1.95)$ & 0.119 \\
IL-8 $(\mathrm{pg} / \mathrm{mL})$ & $82.3(94.12)$ & $78.19(69.07)$ & 0.824 \\
Leptin $(\mathrm{ng} / \mathrm{mL})$ & $2.47(2.21)$ & $4.16(2.30)$ & $<0.001$ \\
CCL5 $(\mathrm{ng} / \mathrm{mL})$ & $68.72(7.92)$ & $61.47(3.62)$ & 0.412 \\
Adiponectin $(\mu \mathrm{mg} / \mathrm{mL})$ & $5.39(3.14)$ & $3.63(2.43)$ & 0.004 \\
IL-1 $\beta(\mathrm{pg} / \mathrm{mL})$ & $1.09(0.21)$ & $1.27(0.30)$ & 0.001 \\
\hline Women $(\mathrm{mean}[\mathrm{SD}])$ & $(\mathrm{n}=22)$ & $(\mathrm{n}=22)$ & \\
IL-6 $(\mathrm{pg} / \mathrm{mL})$ & $1.96(0.75)$ & $2.48(0.95)$ & 0.051 \\
IL-8 $(\mathrm{pg} / \mathrm{mL})$ & $24.44(30.79)$ & $25.05(14.64)$ & 0.929 \\
Leptin $(\mathrm{ng} / \mathrm{mL})$ & $6.83(3.53)$ & $11.34(5.83)$ & 0.003 \\
CCL5 $(\mathrm{ng} / \mathrm{mL})$ & $78.64(32.13)$ & $80.88(42.01)$ & 0.831 \\
Adiponectin $(\mu \mathrm{\mu g} / \mathrm{mL})$ & $9.56(4.74)$ & $9.83(8.15)$ & 0.889 \\
IL-1 $\beta(\mathrm{pg} / \mathrm{mL})$ & $0.48(0.21)$ & $0.64(0.33)$ & 0.072 \\
\hline & & \multicolumn{2}{c}{}
\end{tabular}

$\mathrm{SD}$, standard deviation.

Table 3. Correlation Between Adipose Tissue and Cytokine Levels

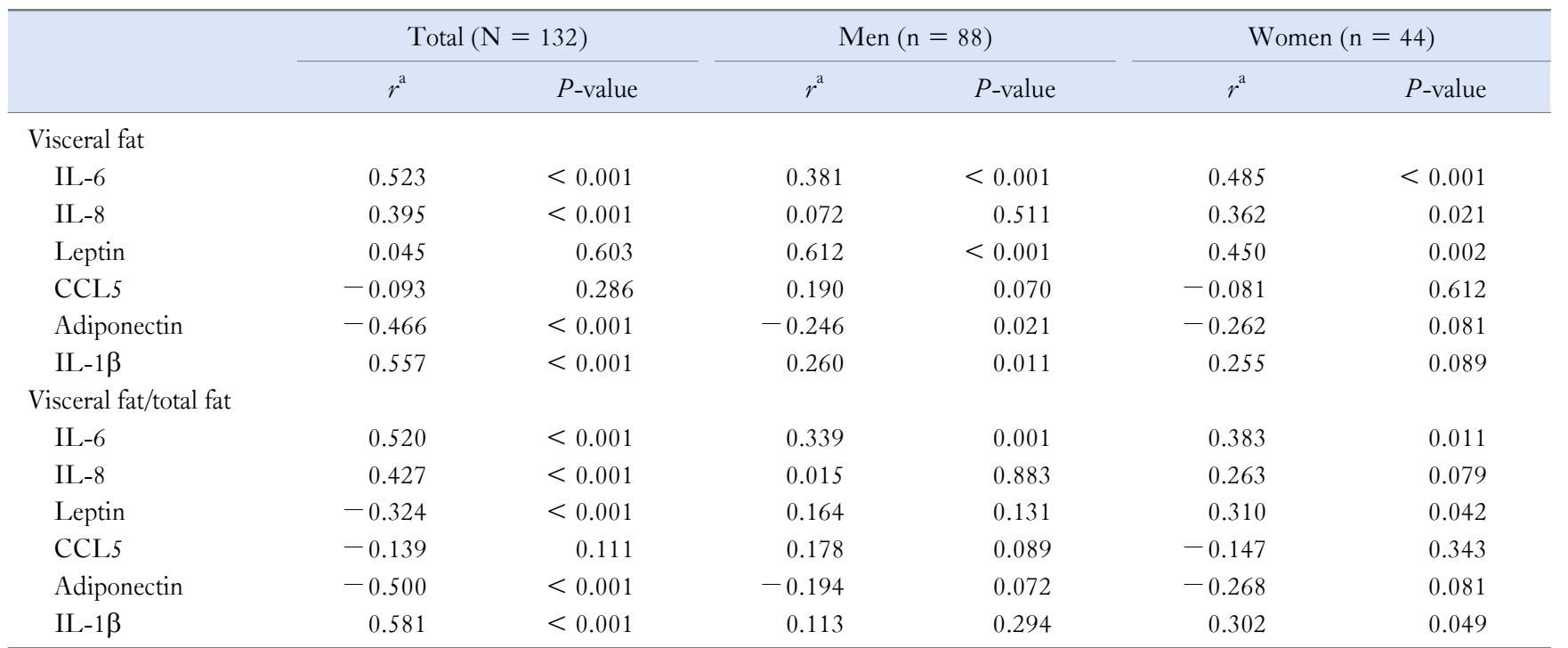

${ }^{a} r$ is the Spearman's correlation coefficient. 


\section{Correlation Between Visceral Adipose Tissue and Cytokines}

Visceral fat was positively correlated with levels of IL-6 $(r=$ $0.523)$, IL-8 ( $r=0.395)$, and IL-1 $\beta(r=0.557)$, but negatively associated with adiponectin $(r=-0.466)$ (Table 3$)$. In sex-specific analysis, the overall results were similar except for leptin, which showed a strong correlation with visceral fat in both sexes ( $r=0.612$ and $0.450 \mathrm{in}$ men and women, respectively). The ratio of visceral fat/total fat also showed a strong positive relationship with IL-6 $(r=0.520)$, IL-8 $(r=0.427)$, and IL-1 $\beta(r=$ $0.581)$, but was negatively associated with leptin $(r=-0.324)$ and adiponectin $(r=-0.500)$ (Table 3$)$. These results were same as with visceral fat except for leptin. Even if leptin has a negative relationship with visceral fat/total fat in overall analysis, it had positive association in women. Sex-specific analysis of the ratio of visceral fat/total fat also showed the same pattern as with visceral fat. The gap between overall and sex-specific analysis in leptin may be due to the significantly different range in leptin by sex (mean is 3.31 and $9.08 \mathrm{ng} / \mathrm{mL}$ in men and women, respectively, $P<0.001)$.

\section{Adjusted Analysis for Both Visceral Fat and Cytokines}

In adjusted analysis for age, sex, hiatal hernia, H. pylori, smoking, alcohol, and one of visceral fat, BMI, and each of cytokines, reflux esophagitis increased in high obesity indexes (visceral fat and BMI) and cytokines (leptin and IL-1 $\beta$ ) (Table 4). However, further adjusted analysis for both inflammatory cytokines and both obesity indexes (visceral fat and BMI) showed that only visceral fat/100 (OR, 4.32; 95\% CI, 2.18-8.58; $P<$
0.001) and leptin (OR, 1.36; 95\% CI, 1.10-1.69; $P=0.005)$ had a positive association with reflux esophagitis.

\section{Discussion}

In this case-control study, visceral fat, BMI, and inflammatory cytokines were increased in individuals with reflux esophagitis compared to controls, and visceral fat showed a strong correlation with levels of inflammatory cytokines. After adjusting for visceral fat, BMI, and cytokines simultaneously, only visceral fat and leptin independently increased the risk of reflux esophagitis, but the effects of other cytokines and body mass index on reflux esophagitis were abolished.

Even if BMI referring general obesity increased the risk of reflux esophagitis in adjusted analysis except visceral fat, BMI had no association with reflux esophagitis in adjusted analysis for both BMI and visceral fat. This result is consistent with results of a previous study. ${ }^{4}$ Previous studies suggested that visceral fat markedly increases the risk of GERD and is a remarkable predictor for reflux esophagitis. ${ }^{4,5}$ Even if visceral fat is strongly correlated with reflux esophagitis ${ }^{4}$ and many metabolic diseases, there is no standard cut off value defining obesity. Therefore, we used visceral fat/total fat ratio as supportive obesity index. Several plausible mechanisms which abdominal obesity increases GERD have been suggested. Abdominal visceral fat may cause reflux through an increase in intra-abdominal pressure and subsequent esophageal acid exposure ${ }^{14,15}$ and is metabolically active and increases inflammatory cytokines. ${ }^{9}$ The cytokines released from visceral fat and leptin released from abdominal visceral fat may also be risk factors for esophageal inflammation, Barrett's esophagus, and esophageal adenocarcinoma. ${ }^{11,12,16}$ In our study, both

Table 4. Multivariate Analysis for Reflux Esophagitis

\begin{tabular}{|c|c|c|c|c|}
\hline & $\begin{array}{c}\text { Adjusted OR } \\
\quad(95 \% \mathrm{CI})^{\mathrm{a}}\end{array}$ & $P$-value & $\begin{array}{c}\text { Adjusted OR } \\
(95 \% \mathrm{CI})^{\mathrm{b}}\end{array}$ & $P$-value \\
\hline Visceral fat $(/ 100)\left(\mathrm{cm}^{3}\right)$ & $2.02(1.56-2.61)$ & $<0.001$ & $4.32(2.18-8.58)$ & $<0.001$ \\
\hline Body masss index $\left(\mathrm{kg} / \mathrm{m}^{2}\right)$ & $1.61(1.32-1.96)$ & $<0.001$ & $0.69(0.43-1.12)$ & 0.129 \\
\hline IL-6 (pg/mL) & $1.17(0.93-1.48)$ & 0.186 & $1.07(0.73-1.55)$ & 0.743 \\
\hline IL-8 (/10) (ng/mL) & $0.99(0.94-1.06)$ & 0.881 & $0.85(0.70-1.03)$ & 0.091 \\
\hline Leptin $(\mathrm{ng} / \mathrm{mL})$ & $1.29(1.12-1.49)$ & $<0.001$ & $1.36(1.10-1.69)$ & 0.005 \\
\hline Adiponectin $(\mu \mathrm{g} / \mathrm{mL})$ & $0.97(0.89-1.05)$ & 0.144 & $0.99(0.83-1.18)$ & 0.934 \\
\hline $\mathrm{IL}-1 \beta(\times 10)(\mathrm{pg} / \mathrm{mL})$ & $1.29(1.08-1.54)$ & 0.006 & $0.84(0.66-1.07)$ & 0.162 \\
\hline
\end{tabular}

${ }^{\mathrm{a}}$ Adjusted for age, sex, hiatal hernia, Helicobacter pylori, smoking, drinking, and one of visceral fat, body mass index, and each cytokine. ${ }^{\mathrm{b}}$ Adjusted for age, sex, hiatal hernia, H. pylori, smoking, drinking, visceral fat, body mass index, and all cytokines.

All variables are continuous variables. 
visceral fat and the visceral fat/total fat ratio showed a strongly positive correlation with IL-6, IL-8, and IL-1 $\beta$, but were negatively associated with adiponectin. Leptin in overall analysis showed no association with visceral fat but showed a strong association with the visceral fat/total fat ratio. With sex-specific analysis, the results were similar to the overall results except for leptin, which showed a strong correlation with visceral fat in both men and women.

Several mechanisms have been proposed for how cytokines induce reflux esophagitis. First, inflammatory cytokines such as IL-1 and IL-6 can reduce esophageal muscle contraction by inhibiting acetylcholine release. ${ }^{17,18}$ Second, some studies have suggested that reflux may cause esophagitis through a cytokine-mediated mechanism rather than because of injury due to acid. ${ }^{19}$ Exposure of esophageal cells to acidified bile salts increases the secretion of IL- 8 and IL- $1 \beta$, and conditioned media from these cells increases the migration rates of $\mathrm{T}$ cells and neutrophils. ${ }^{20}$ These findings support a hypothesis for the development of reflux esophagitis in which refluxed gastric acid stimulates esophageal epithelial cells to secrete chemokines that mediate damage to esophageal tissue.

Several studies have suggested that mucosal cytokines are increased in GERD. ${ }^{20,21}$ In 22 patients with non-erosive reflux disease, mucosal levels of cytokines (IL-8, IL-1 $\beta$, and CCL5) had a positive with recurrent reflux symptoms. ${ }^{20}$ The relative IL-8 mRNA expression are significantly higher in esophageal mucosa of non-erosive reflux disease than controls, and lansoprazole treatment significantly reduces IL-8 mRNA expression levels. ${ }^{21}$ However, no reports have described the relationship between circulating cytokines and reflux esophagitis, although several studies have shown the association between circulating cytokines and Barrett's esophagus. ${ }^{22}$ In our study, circulating inflammatory cytokines such as IL-1 $\beta$, were increased in reflux esophagitis with adjusted analysis, even though its effect on reflux esophagitis was abolished with additional adjusted analysis for visceral fat and BMI. As far as we know, this is the first report to show the association between circulating cytokines and reflux esophagitis.

Several studies have suggested a relationship between leptin and Barrett's esophagus. Leptin, which is secreted by adipocytes, is a peptide that signals satiety to the brain. Most obese persons are resistant to this signal and therefore have elevated blood leptin levels. Patients with Barrett's esophagus have significantly higher fundic leptin levels compared with a normal esophagus. ${ }^{23}$ High serum leptin is associated with Barrett's esophagus in men but not women. ${ }^{24}$ In a case-control study of Barrett's esophagus com- pared with controls (50 matched pairs), Barrett's esophagus was inversely associated with the plasma adiponectin level, suggesting that adiponectin may be involved in the etiology of Barrett's esophagus. ${ }^{25}$ Although data from several studies support an association between leptin or adiponectin and Barrett's esophagus, no report has shown a relationship between leptin and reflux esophagitis. In our study, leptin was markedly increased in reflux esophagitis compared to normal controls in both overall and sex-specific analysis. Furthermore, simultaneous evaluation of visceral fat and cytokines to assess the effect on reflux esophagitis has not been reported. With adjusted analysis for many confounding factors including visceral fat, an increase of $1 \mathrm{ng} / \mathrm{mL}$ leptin increased reflux esophagitis 1.3-fold, but the effect of other cytokines was abolished. This is the first study simultaneously considering the effect of visceral fat and inflammatory cytokines or adipokines on reflux esophagitis.

A Japanese study showed that adiponectin is negatively associated with gastroesophageal reflux symptoms. ${ }^{26}$ In our study, adiponectin had no overall relationship with reflux esophagitis. But sex-specific analysis showed a decrease in adiponectin in reflux esophagitis in men but not in women. Sexual differences in circulating adipokine concentrations were reported in the fasting state and after an oral glucose challenge. ${ }^{27}$ One study showed that the observed sex difference in the relationship between C-reactive protein and adiposity almost disappears upon adjustment for leptin, suggesting that these sex differences may be partially mediated by leptin. ${ }^{28}$ In our study, the levels of leptin (3.31 and 9.08 $\mathrm{ng} / \mathrm{mL}$ in men and women, respectively) and adiponectin (4.51 and $9.69 \mu \mathrm{g} / \mathrm{mL}$ in men and women, respectively) were more than 2-fold different between men and women. Although visceral fat had a strong positive relationship with leptin in sex-specific analysis, no association was seen in overall analysis. These results occurred because of the sex-specific distribution of leptin and visceral fat. Although visceral fat in men was about 2-fold higher compared to women, the circulating leptin level in men was lower than in women.

Our study has several limitations. First, the case-control design involving cross-sectional assessments is limited in establishing a causal relationship. Longitudinal studies should be used to clarify the causality of the association. Second, a case-control study can have selection bias compared to population-based studies. To minimize the selection bias, we selected age- and sex-matched controls from the same period and the same population undergoing a health check-up. The last is relative small sample size. But there were no borderline results. Therefore even 
if sample size increases, the effect on the main outcomes will be limited. Our study also has several remarkable strengths. Only patients with newly diagnosed reflux esophagitis were enrolled, reducing the potential effects of previous acid suppression treatment. The selection of persons undergoing a health check-up was not influenced by the presence of the outcome conditions, which reduces the risk of selection bias. Finally, we measured several important potential confounders and adjusted for those in our analyses.

In summary, inflammatory cytokines, adipokines, and obesity including BMI referring general obesity and visceral fat referring abdominal obesity had an association with reflux esophagitis. However, the effect of inflammatory cytokines and BMI on reflux esophagitis was abolished after simultaneously adjusting for visceral fat, body mass index, and cytokines, and this finding seems to suggest that visceral fat may cause reflux esophagitis by increasing inflammatory cytokines. Interestingly, abdominal visceral fat and leptin independently increased the risk of reflux esophagitis.

\section{References}

1. El-Serag HB, Petersen NJ, Carter J, et al. Gastroesophageal reflux among different racial groups in the United States. Gastroenterology 2004;126:1692-1699.

2. Cho YS, Choi MG, Jeong JJ, et al. Prevalence and clinical spectrum of gastroesophageal reflux: a population-based study in Asan-si, Korea. Am J Gastroenterol 2005;100:747-753.

3. Ronkainen J, Agréus L. Epidemiology of reflux symptoms and GORD. Best Pract Res Clin Gastroenterol 2013;27:325-337.

4. Nam SY, Choi IJ, Ryu KH, Park BJ, Kim HB, Nam BH. Abdominal visceral adipose tissue volume is associated with increased risk of erosive esophagitis in men and women. Gastroenterology 2010;139:1902-1911, e2.

5. Chung SJ, Kim D, Park MJ, et al. Metabolic syndrome and visceral obesity as risk factors for reflux oesophagitis: a cross-sectional case-control study of 7078 Koreans undergoing health check-ups. Gut 2008;57:1360-1365.

6. Singh S, Sharma AN, Murad MH, et al. Central adiposity is associated with increased risk of esophageal inflammation, metaplasia, and adenocarcinoma: a systematic review and meta-analysis. Clin Gastroenterol Hepatol 2013;11:1399-1412, e7.

7. El-Serag HB, Hashmi A, Garcia J, et al. Visceral abdominal obesity measured by $\mathrm{CT}$ scan is associated with an increased risk of Barrett's oesophagus: a case-control study. Gut 2014;63:220-229.

8. Pandolfino JE, El-Serag HB, Zhang Q, Shah N, Ghosh SK, Kahrilas PJ. Obesity: a challenge to esophagogastric junction integrity. Gastroenterology 2006;130:639-649.

9. Kahn SE, Hull RL, Utzschneider KM. Mechanisms linking obesity to insulin resistance and type 2 diabetes. Nature 2006;444:840-846.

10. Calabro P, Yeh ET. Intra-abdominal adiposity, inflammation, and cardiovascular risk: new insight into global cardiometabolic risk. Curr Hypertens Rep 2008;10:32-38.

11. Coussens LM, Werb Z. Inflammation and cancer. Nature 2002; 420:860-867.

12. Ryan AM, Duong M, Healy L, et al. Obesity, metabolic syndrome and esophageal adenocarcinoma: epidemiology, etiology and new targets. Cancer Epidemiol 2011;35:309-319.

13. Nam SY, Choi IJ, Nam BH, Park KW, Kim CG. Obesity and weight gain as risk factors for erosive esophagitis in men. Aliment Pharmacol Ther 2009;29:1042-1052.

14. El-Serag HB, Ergun GA, Pandolfino J, Fitzgerald S, Tran T, Kramer JR. Obesity increases oesophageal acid exposure. Gut 2007;56:749-755.

15. El-Serag HB, Tran T, Richardson P, Ergun G. Anthropometric correlates of intragastric pressure. Scand J Gastroenterol 2006;41: 887-891.

16. Rubenstein JH, Morgenstern $\mathrm{H}, \mathrm{McC}$ conell $\mathrm{D}$, et al. Associations of diabetes mellitus, insulin, leptin, and ghrelin with gastroesophageal reflux and Barrett's esophagus. Gastroenterology 2013;145:12371244, e1-e5.

17. Cheng L, Cao W, Fiocchi C, Behar J, Biancani P, Harnett KM. Platelet-activating factor and prostaglandin E2 impair esophageal ACh release in experimental esophagitis. Am J Physiol Gastrointest Liver Physiol 2005;289:G418-G428.

18. Cheng L, Cao W, Behar J, Biancani P, Harnett KM. Inflammation induced changes in arachidonic acid metabolism in cat LES circular muscle. Am J Physiol Gastrointest Liver Physiol 2005;288:G787G797.

19. RiSouza RF, Huo X, Mittal V, et al. Gastroesophageal reflux might cause esophagitis through a cytokine-mediated mechanism rather than caustic acid injury. Gastroenterology 2009;137:1776-1784.

20. Isomoto $\mathrm{H}$, Wang $\mathrm{A}$, Nishi $\mathrm{Y}$, et al. Interleukin 8 and 1 beta and RANTES levels in esophageal mucosa predict recurrence of endoscopy-negative gastroesophageal reflux disease. Hepatogastroenterology 2008;55:482-485.

21. Isomoto H, Saenko VA, Kanazawa Y, et al. Enhanced expression of interleukin-8 and activation of nuclear factor kappa-B in endoscopy-negative gastroesophageal reflux disease. Am J Gastroenterol 2004;99:589-597.

22. Garcia JM, Splenser AE, Kramer J, et al. Circulating inflammatory cytokines and adipokines are associated with increased risk of Barrett's esophagus: a case-control study. Clin Gastroenterol Hepatol 2014; 12:229-238, e3.

23. Francois F, Roper J, Goodman AJ, et al. The association of gastric leptin with oesophageal inflammation and metaplasia. Gut 2008;57: 16-24.

24. Kendall BJ, Macdonald GA, Hayward NK, et al. Leptin and the risk of Barrett's oesophagus. Gut 2008;57:448-454.

25. Rubenstein JH, Dahlkemper A, Kao JY, et al. A pilot study of the association of low plasma adiponectin and Barrett's esophagus. Am J Gastroenterol 2008;103:1358-1364.

26. Iwasaki E, Suzuki H, Sugino Y, et al. Decreased levels of adiponectin in obese patients with gastroesophageal reflux evaluated by videoesophagography: possible relationship between gastroesophageal reflux and metabolic syndrome. J Gastroenterol Hepatol 2008; 23(suppl 2):S216-S221. 
27. Luque-Ramírez M1, Martínez-García MÁ, Montes-Nieto R, et al. Sexual dimorphism in adipose tissue function as evidenced by circulating adipokine concentrations in the fasting state and after an oral glucose challenge. Hum Reprod 2013;28:1908-1918.
28. Rossi IA, Bochud M, Bovet $\mathrm{P}$, et al. Sex difference and the role of leptin in the association between high-sensitivity C-reactive protein and adiposity in two different populations. Eur J Epidemiol 2012;27: 379-384. 